\title{
OTIMIZAÇÃO DE BRANQUEAMENTO DE ÓLEO DE FARELO DE ARROZ COM BLENDAS DE ADSORVENTES
}

\author{
M. M. STRIEDER ${ }^{1}$; V. S. de BORBA ${ }^{1}$, C. P. PINHEIRO ${ }^{1}$, e R. S. POHNDORF ${ }^{1}$, L. A. A. \\ PINTO $^{1}$
}

${ }^{1}$ Universidade Federal do Rio Grande, Escola de Química e Alimentos

E-mail para contato: dqmpinto@furg.br

\begin{abstract}
RESUMO - O objetivo neste trabalho foi otimizar o branqueamento de óleo de farelo de arroz para a quantidade de adsorvente e a concentração de blendas de carvão ativado/terra ativada através de metodologia de superfície de resposta. $\mathrm{O}$ efeito linear da quantidade de adsorvente e o efeito quadrático da concentração carvão/terra foram os efeitos mais significativos tanto para carotenóides quanto para o índice de peróxidos. A análise dos efeitos indicou que a utilização de blendas de carvão ativado/terra ativada proporcionou uma redução no índice de peróxidos e um aumento no teor de carotenóides após o branqueamento. Uma redução de mais de $80 \%$ no índice de peróxidos foi obtida utilizando $1 \%$ de adsorvente e $8 \%$ de blenda de carvão/terra. Nesta condição o teor de carotenóides foi de $6,98 \pm 0,16 \mathrm{meq} \mathrm{kg}^{-1}$. Os modelos estatísticos gerados para descrever a variação no teor de carotenóides e o índice de peróxidos durante o branqueamento foram significativos e preditivos.
\end{abstract}

\section{INTRODUÇÃO}

O arroz (Oriza Sativa L.) é um cereal consumido mundialmente e produzido principalmente no continente asiático e no sul da América do sul. $\mathrm{O}$ óleo de farelo de arroz (OFA) apresenta antioxidantes naturais como y-orizanol, tocoferóis e tocotrienóis que estão associados à prevenção de doenças, devido sua ação antiinflamatória (Lerma-García et al., 2009). Os principais ácidos graxos encontrados no OFA são o palmítico $(19,8 \%)$, oléico $(42,7 \%)$ e linoléico $(32,4 \%)$, e o teor de insaponificáveis é de 5,4\% (Van Hoed et al., 2006). As etapas de refino de óleo de farelo de arroz normalmente incluem degomagem, neutralização, branqueamento, deceramento e desodorização (Pestana-Bauer et al., 2012). Nestas etapas impurezas são removidas do óleo bruto para obtenção de um óleo refinado com características aceitáveis para consumo humano. Entretanto, as etapas do processo devem ser estudadas a fim maximizar a qualidade do óleo e minimizar as perdas de compostos de interesse nutricional.

$\mathrm{Na}$ etapa de branqueamento de óleos, a operação unitária de adsorção é utilizada para remover compostos indesejados, alterando a cor pela retirada de pigmentos e removendo produtos de oxidação como peróxidos, aldeídos e cetonas. Os fatores que mais interferem na etapa de branqueamento de óleos são a temperatura, pressão, agitação e concentração de adsorvente. A indústria de óleos utiliza largamente terra ativada como adsorvente devido seu baixo custo. Porém, o carvão ativado destaca-se pela elevada área superficial e porosidade. A 
utilização de blendas de diferentes adsorventes ganha importância na busca por óleos branqueados com maior estabilidade oxidativa (Monte et al., 2015).

O objetivo neste estudo foi otimizar a etapa de branqueamento de óleo de farelo de arroz utilizando metodologia de superfície de resposta. Os fatores de estudo foram a quantidade de adsorvente e a concentração de blendas de carvão ativado/terra ativada. $\mathrm{O}$ teor de carotenóides e o índice de peróxidos foram utilizados como resposta.

\section{MATERIAIS E MÉTODOS}

\subsection{Materiais}

$\mathrm{O}$ óleo de farelo de arroz (OFA) neutralizado foi mantido à $-20{ }^{\circ} \mathrm{C}$ para reduzir $\mathrm{o}$ processo oxidativo. Os experimentos foram realizados no Laboratório de Operações Unitárias da Universidade Federal do Rio Grande (FURG). Foi utilizado terra ativada (Tonsil Supreme $110 \mathrm{FF}$ ) e carvão ativado como adsorventes comerciais nos ensaios de branqueamento.

\subsection{Análise de carotenóides e peróxidos}

O teor de carotenóides foi determinado por espectrofotômetro na região visível (Quimis, Q108, Brasil). Amostras de OFA foram diluídas em hexano $(10 \% \mathrm{~m} / \mathrm{v})$ e filtradas. Leituras de absorbância foram realizadas à $446 \mathrm{~nm}$ e o teor de carotenóides foi expresso em $\mathrm{mg} \mathrm{kg}^{-1}$, de acordo com a Equação 1, segundo metodologia proposta em MPOB Test Method (2005),

$$
C=\frac{383 A_{446}}{L c}
$$

onde $C$ é a concentração de carotenóides $\left(\mathrm{mg} \mathrm{kg}^{-1}\right), A$ é a leitura de absorbância em $446 \mathrm{~nm}$, $L$ é o comprimento da cubeta $(\mathrm{cm}), c$ é a concentração da solução de óleo em hexano $(\mathrm{g}$ $100 \mathrm{ml}^{-1}$ ) e 383 é o coeficiente de extinção para carotenóides. Os produtos de oxidação primária foram determinados através do índice de peróxidos $(P)$ de acordo com o método $\mathrm{Cd}$ 8-53 da AOCS (1998), e expresso em meq kg-1 óleo.

\subsection{Experimentos de branqueamento}

Amostras de $30 \mathrm{~g}$ de OFA neutralizado foram aquecidas a $120 \pm 1{ }^{\circ} \mathrm{C}$ sob agitação constante (40 RPM), utilizando um agitador magnético com aquecimento. A taxa de aquecimento foi de $7{ }^{\circ} \mathrm{C} \mathrm{min}{ }^{-1} \mathrm{e}$ o óleo foi mantido à pressão absoluta de $40 \mathrm{mmHg}$. Após atingir a temperatura, o adsorvente foi adicionado ao óleo de acordo com a matriz de planejamento experimental. $\mathrm{O}$ tempo de contato entre o adsorvente e o óleo durante o branqueamento foi de $20 \mathrm{~min}$. O óleo foi separado do adsorvente por filtração à vácuo utilizando pré-capa com terra diatomácea durante $15 \mathrm{~min}$, totalizando $35 \mathrm{~min}$ de experimento. Os experimentos foram realizados em réplica. As amostras foram analisadas quanto ao teor de carotenóides e índice de peróxidos.

\subsection{Planejamento experimental e análise estatística}


$\mathrm{O}$ estudo do branqueamento de OFA foi realizado por meio de um delineamento composto central rotacional (DCCR), incluindo 4 pontos axiais e 3 pontos centrais para geração do erro (Tabela 1). As variáveis estudadas foram a quantidade de adsorvente adicionada ao óleo $(A d)$ e a concentração de blendas de carvão ativado e terra ativada $(C T)$. Análise de variância foi utilizada para validação dos modelos, verificando o coeficiente de determinação $\left(\mathrm{R}^{2}\right)$ e o teste F através do programa Statistic 7.0 (StatSoft, USA).

\section{RESULTADOS E DISCUSSÃO}

A tabela 1 apresenta o teor de carotenóides e o índice de peróxidos para a matriz do planejamento experimental. O branqueamento de OFA foi responsável pela redução máxima de $65 \%$ dos carotenóides e $82 \%$ dos peróxidos, nos experimentos 8 e 4 , respectivamente. Durante o branqueamento, os adsorventes interagem com compostos de maior afinidade no óleo, ocorrendo adsorção. Entretanto, a influência das altas temperaturas pode provocar reações de oxidação, gerando produtos de oxidação primária e secundária. Carotenóides possuem ação antioxidante, ou seja, sua retirada em excesso pode provocar a formação de produtos de oxidação (Monte et al., 2015). Utilizando 1\% de adsorvente e $8 \%$ da blenda carvão/terra (experimento 4), o índice de peróxidos apresentou o menor valor. Resultado semelhante foi encontrado por Morais et al. (2001), estudando o refino de óleo de pescado, onde o menor índice de peróxidos foi obtido adicionando $10 \%$ de carvão ativado na quantidade total de adsorvente.

Tabela 1 - Carotenóides e peróxidos em função das condições de branqueamento de OFA

\begin{tabular}{|c|c|c|c|c|}
\hline Experimento & Adsorvente (\%) & Carvão/Terra (\%) & $\begin{array}{l}\text { Carotenóides } \\
\left(\mathrm{mg} \mathrm{kg}^{-1}\right)\end{array}$ & $\begin{array}{l}\text { Peróxidos } \\
\left(\text { meq kg-1) }^{-1}\right)\end{array}$ \\
\hline 1 & ${ }^{*}-1(0,50)$ & $-1(2,00)$ & $8,83 \pm 0,03$ & $4,57 \pm 0,11$ \\
\hline 2 & $-1(0,50)$ & $+1(8,00)$ & $9,03 \pm 0,20$ & $5,07 \pm 0,20$ \\
\hline 3 & $+1(1,00)$ & $-1(2,00)$ & $7,28 \pm 0,12$ & $2,71 \pm 0,08$ \\
\hline 4 & $+1(1,00)$ & $+1(8,00)$ & $6,98 \pm 0,16$ & $2,22 \pm 0,10$ \\
\hline 5 & $0(0,75)$ & $-1,414(0,77)$ & $7,79 \pm 0,11$ & $2,79 \pm 0,07$ \\
\hline 6 & $0(0,75)$ & $+1,414(9,23)$ & $8,40 \pm 0,06$ & $3,67 \pm 0,18$ \\
\hline 7 & $-1,41(0,40)$ & $0(5,00)$ & $10,18 \pm 0,21$ & $5,47 \pm 0,35$ \\
\hline 8 & $+1,41(1,10)$ & $0(5,00)$ & $5,72 \pm 0,08$ & $3,57 \pm 0,35$ \\
\hline 9 & $0(0,75)$ & $0(5,00)$ & $6,45 \pm 0,13$ & $4,31 \pm 0,06$ \\
\hline 10 & $0(0,75)$ & $0(5,00)$ & $6,60 \pm 0,12$ & $4,27 \pm 0,01$ \\
\hline 11 & $0(0,75)$ & $0(5,00)$ & $6,59 \pm 0,08$ & $4,25 \pm 0,05$ \\
\hline
\end{tabular}

*valores codificados (valores reais)

A Figura 1 apresenta o diagrama de Pareto para os efeitos estimados das variáveis de processo estudadas. O efeito linear da quantidade de adsorvente adicionada ao óleo foi o fator que mais influenciou a variação de carotenóides (Figura 1A). Assim, à medida que se aumenta a quantidade de adsorvente, mais carotenóides são retirados do óleo, como era esperado. Os efeitos quadráticos da relação carvão/terra e da quantidade de adsorvente 
também foram significativos $(\mathrm{p}<0,05)$. A análise dos efeitos indicou que a adição de carvão ativado na terra ativada favoreceu a permanência de carotenóides no óleo após o branqueamento.

O efeito linear da quantidade adsorvente e o efeito quadrático da relação carvão/terra foram significativos $(\mathrm{p}<0,05)$ no processo de adsorção de peróxidos (Figura 1B). Assim como ocorreu com o teor de carotenóides, o aumento da quantidade de adsorvente ao óleo durante o branqueamento favoreceu a diminuição no índice de peróxidos. Porém, a relação carvão/terra apresentou efeito quadrático negativo, evidenciando a importância da blenda com carvão ativado para remoção de produtos de oxidação.

Figure 1 - Diagrama de Pareto dos efeitos estimados das variáveis de processo no teor de carotenóides (A) e no índice de peróxidos (B).
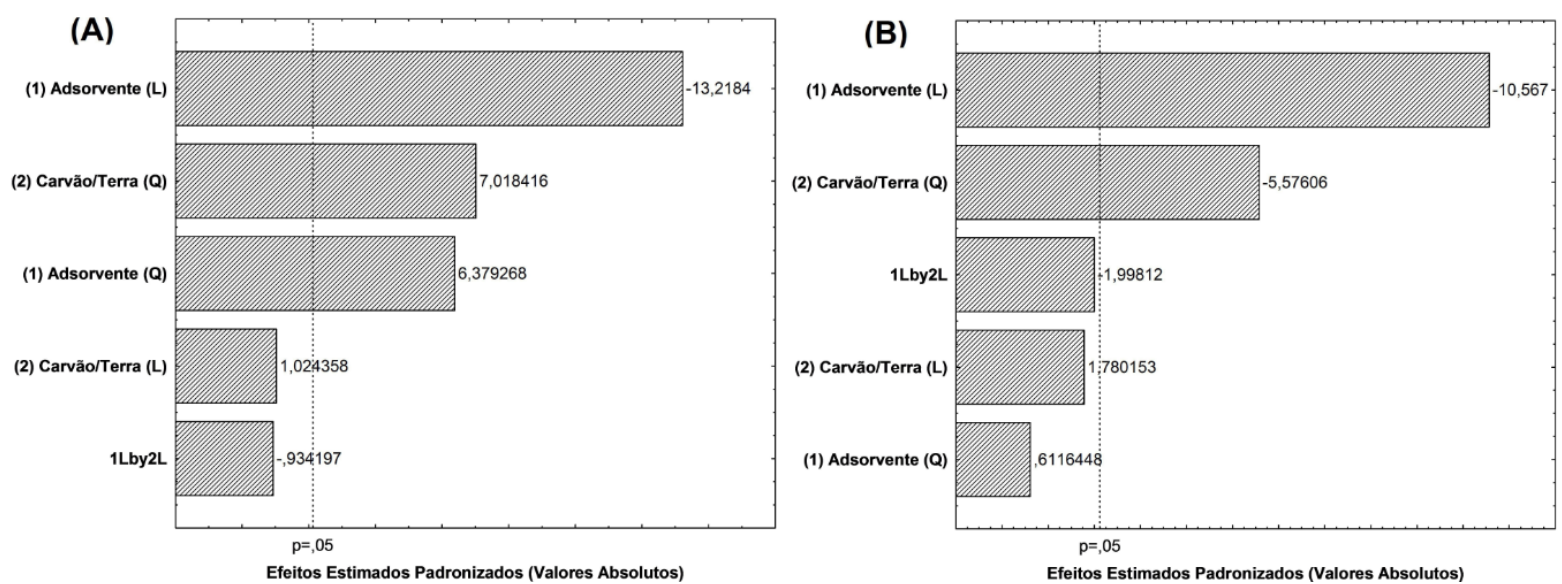

Através do delineamento experimental foram gerados modelos estatísticos para avaliar o processo de branqueamento de FAO quanto ao teor de carotenóides e índice de peróxidos. A análise de variância dos modelos foi realizada utilizando os efeitos significativos das variáveis de processo. $\mathrm{O}$ modelo obtido para avaliar as mudanças no teor de carotenóides $(C)$ durante o branqueamento (Equação 2) apresentou coeficiente de determinação $\mathrm{R}^{2}=0,93$, evidenciando que o modelo foi significativo. O teste $\mathrm{F}$ apresentou valor de 25,9 , ou seja, o modelo é capaz de predizer a variação de carotenóides no processo de branqueamento de FAO, para os níveis estudados.

$C=6,53-1,24 A d+0,71 A d^{2}+0,78 C T^{2}$

O modelo obtido para descrever as variação no índice de peróxidos $(P)$ durante o branqueamento de FAO é apresentado na Equação 3. A análise de variância deste modelo sugere um coeficiente de determinação $R^{2}=0,91$ e valor de teste $F=16,95$. Consequentemente, o modelo além de significativo é preditivo.

$P=4,33-0,92 A d-0,60 C T^{2}$ 
Através da análise das superfícies de resposta, observou-se que a utilização de $0,5 \%$ de adsorvente manteve elevado o teor de carotenóides no óleo durante o branqueamento (Figura 2A). Entretanto, a diminuição em excesso da quantidade de adsorvente $(<0,75 \%)$ provoca a baixa adsorção de peróxidos, conforme é observado na Figura $2 \mathrm{~B}$. Utilizando $0,75 \%$ de adsorvente e aproximadamente $10 \%$ da blenda carvão/terra o índice de peróxidos foi reduzido quase $70 \%$ do óleo neutralizado para o óleo branqueado. Carotenóides residuais podem ser degradados termicamente durante a etapa de desodorização, assim, é importante a remoção principalmente de produtos de oxidação durante o branqueamento.

Figure 2 - Superfícies de resposta do branqueamento de FAO para o teor de carotenóides (A) e índice de peróxidos (B).

(A)

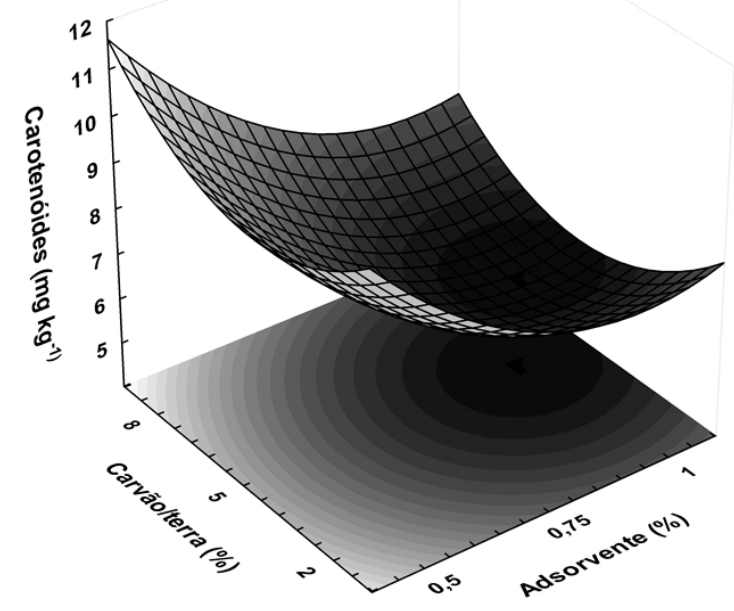

(B)

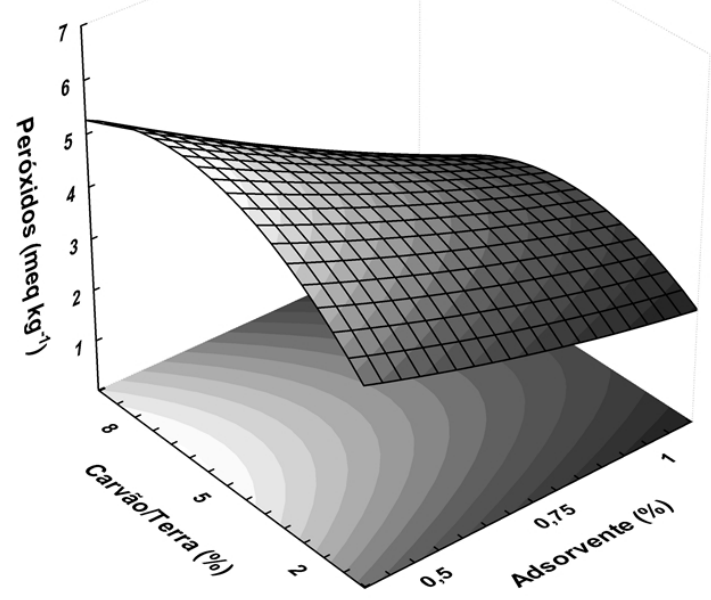

\section{CONCLUSÃO}

O branqueamento de óleo de farelo de arroz foi otimizado quanto a quantidade de adsorvente e a concentração das blendas de carvão/terra. A otimização do branqueamento foi realizada através da metodologia de superfície de resposta. A melhor condição de branqueamento foi obtida utilizando $1 \%$ de adsorvente e $8 \%$ de blenda carvão/terra, removendo mais de $80 \%$ dos produtos de oxidação primária e $40 \%$ de carotenóides. Ambos os modelos gerados para avaliar o teor de carotenóides e o índice de peróxidos durante o branqueamento foram significativos e preditivos.

\section{REFERÊNCIAS}

AOCS. Official and tentative methods of the American Oil Chemist's Society. Chicago, USA: American Oil Chemists' Society Press, 1998. 
LERMA-GARCÍA, M. J.; HERRERO-MARTÍNEZ, J. M.; SIMÓ-ALFONSO, E. F.; MENDONÇA, C. R. B.; RAMIS-RAMOS, G. Composition, industrial processing and applications of rice bran $\gamma$-oryzanol. Food Chem., v. 115, p. 389-404, 2009.

MONTE, M. L., MONTE, M. L., POHNDORF, R. S., CREXI, V. T. AND PINTO, L. A. A. Bleaching with blends of bleaching earth and activated carbon reduces color and oxidation products of carp oil. Eur. J. Lipid Sci. Technol, in press, 2015.

MORAIS, M. M.; PINTO, L. A. A.; ORTIZ, S. C. A.; CREXI, V. T.; SILVA, R. L.; SILVA, J. D. Estudo do processo de refino do óleo de pescado. Rev. Inst. Adolfo Lutz, v. 60, p.23-33, 2001.

MPOB Test Method. Determination of Carotene Content. Malaysian Palm Oil Board, Method $\mathrm{n}^{\mathrm{o}}$. p 2.6, p. 194-197, 2005.

PESTANA-BAUER, V. R.; ZAMBIAZI, R. C.; MENDONÇA, C. R. B.; BENEITOCAMBRA, M.; RAMIS-RAMOS, G. y-oryzanol and tocopherol contents in residues of rice bran oil refining. Food Chem., v. 134, p. 1479-1483, 2012.

VAN HOED V.; DEPAEMELAERE, G.; VILA AYALA, J.; SANTIWATTANA, P.; VERHÉ R.; DE GREYT, W. Influence of Chemical Refining on the Major and Minor Components of Rice Bran Oil. J. Am. Oil Chem. Soc., v. 83, p. 315-321, 2006. 